\title{
Effect of P10 Cemented Carbide Cutting Tools Subjected to Electromagnetic Coupling Field Treatment on the Surface Roughness of Machined 45 Steel
}

\section{Fu Zhong}

Sichuan University

Min Yuan

Sichuan University

\section{Dehao Meng}

Chengdu, Sichuan 610065

\section{Li Wang}

Sichuan University

Jie Wang

Sichuan University

Jian Liu

Sichuan University

Kunlan Huang ( $\square$ rose15682013726@163.com )

Sichuan University https://orcid.org/0000-0003-4001-7651

\section{Yankang Tian}

University of Strathclyde

\section{Research Article}

Keywords: Electromagnetic coupling field, Workpiece surface roughness, Residual stress, Friction coefficient

Posted Date: February 17th, 2021

DOI: https://doi.org/10.21203/rs.3.rs-201997/v1

License: (1) This work is licensed under a Creative Commons Attribution 4.0 International License. Read Full License 


\section{Abstract}

Reducing the surface roughness of machined workpieces is of great interest owing to its potential for improving the quality of finished items and decreasing the cost of machining processes by reducing the need for post processing. This paper contributes to this research by analyzing the effect of P10 cemented carbide cutting tools subjected to pulsed electromagnetic coupling field processing (EMCFP) treatment on the surface roughness of machined 45 steel workpieces. The effects of untreated and EMCFP-treated cutting tools on workpiece surface roughness, tool lifetime, friction coefficient, electron paramagnetic resonance (EPR) spectra, dislocation density and residual stress are compared. The experimental results demonstrate that EMCFP treatment can reduce the average surface roughness of workpieces by $39.2 \%$, enhance tool lifetime by a factor of 1.92 , reduce the friction coefficient by $11.4 \%$, increase the intensities of peak EPR signals, increase the dislocation density by $38 \%$ and decrease the residual stress of the tool flank face by $51.4 \%$. This research provides scientific data and technical support for EMCFP technology with important scientific significance.

\section{Introduction}

The surface quality of machined metal workpieces has a significant influence on the functional behavior and reliability of machine parts. In this regard, the surface roughness of workpieces is one of the most important features reflecting surface quality $[1,2]$. The surface roughness of workpieces has been demonstrated to be influenced by the cutting tool material, tool geometry, the mechanical properties of the workpiece material, and cutting mode [3]. Among these, the tool material is the primary factor affecting the surface roughness [4]. This has led to the wide-scale development of cutting tools and various conditioning treatments for enhancing their mechanical properties.

Among the many proposed tool conditioning treatments, the application of magnetic fields, electric fields, and combined magnetic fields and electric currents, in what is herein denoted as electromagnetic coupling field processing (EMCFP) treatment, has been demonstrated to enhance the mechanical properties of tool materials, improve tool cutting performance, and reduce residual stress. Moreover, the approach has numerous advantages, such as environmental friendliness, fast and economical tool treatment. For example, Dehghani et al. [5] applied a magnetic field to both cutting tool and workpiece simultaneously, and thereby reduced the flank-face wear of the tool by $94 \%$, reduced the cutting force by $66 \%$, and modified the tribology of the tool/workpiece interface. Tharajak et al. [6] deposited poly(etherether-ketone) (PEEK) coatings on low-carbon steel by thermal spray coating in the presence of a magnetic field. The results indicated that the optimum magnetic field enhanced coating properties, resulting in a reduced friction coefficient and increased wear resistance. Zhang et al. [7] applied a magnetic field during the processing of a titanium alloy, and the tensile stress was observed to be decreased by $24 \%$ owing to the homogenization of the residual stress via the excitation of dislocation relaxations by the magnetic field. Xu et al. [8] investigated the influence of pulsed magnetic field treatment on the microstructure of TC4 titanium alloy. The dislocation density was observed to increase about by $10.9 \%$ owing to the excitation of the pulsed magnetic field changing the energy state of electrons in the pinning area of 
dislocations, which led to enhanced dislocation movement and the transformation of the microstructure. Ma et al. [9] investigated the effect of applying pulsed magnetic field treatment to micro-tools on the tool wear, cutting force, and surface roughness of the machined workpiece. The results demonstrated that the surface roughness of the workpiece was reduced when machining ferromagnetic workpiece materials. Song et al. [10] investigated the tribological properties of GCr15 steel under an alternating magnetic field. Microstructural analyses of the magnetic field treated material demonstrated that the substantially improved wear resistance of the treated material was due to increased dislocation density. Similarly, Xi et al. [11] observed substantially increased wear resistance and dislocation density for AISI 1045 steel after the application of a pulsed magnetic field. Xiang et al. [12] investigated the effect of pulsed electric currents on the dislocation density and residual stress of quenched samples. Both drift electrons and Joule heating effects were found to promote the dynamic behavior of dislocations, which decreased the residual stress dramatically. Jung et al. [13] investigated the effect of pulsed electric currents on the growth of fatigue cracks in an aluminum alloy. The results demonstrated that the optimum pulsed electric current treatment increased the fatigue life of aluminum alloy by $55 \%$ owing to the repair of fatigue cracks by local melting on the crack surface. Zhang et al. [14] studied the effect of pulse current on the residual stress of quenched steel, and found that the electronic drift had a direct impact on the dislocation motion and contributed to the plastic strain. In addition, the dislocation caused by electronic wind was also found at the position of thermal activation. Under the influence of electron drift, the motion of vacancy and dislocation accelerates the annihilation of dislocation. Liu et al. [15] applied EMCFP treatment to cemented carbide machining tools, and demonstrated that the proposed treatment promoted dislocation movement and decreased the wear loss of the tools by nearly $35 \%$. Yuan et al. [16,17] researched the influences of the electromagnetic coupling field (TEMCP) on the carbide tool life and cutting performance. The experiments reveal that the optimally treated tools exhibit a fracture toughness increased by $18 \%$, an average cutting temperature decreased by $10 \%$, a friction coefficient for the rank face decreased by $7.9 \%$, and that the magnetic intensity is a dominant factor.

The above-discussed results demonstrate that the application of magnetic fields, electric fields, and combined magnetic and electric fields increases cutting tool lifetime by improving wear resistance, and the indentation fracture toughness of the tools increased a lot. As such, the application of magnetic and electric fields can be expected to reduce the surface roughness of workpieces by reducing surface irregularities on the flank face of cutting tools and therefore reducing friction at the tool/workpiece interface. Moreover, the macro-residual stress of cutting tools has a close relationship with the quality of machined surfaces [18]. Therefore, the reduced residual stress provided by the application of magnetic and electric fields can be expected to yield further benefits toward reducing the surface roughness of machined workpieces. However, no past studies have investigated the effect of EMCFP treatment on the surface roughness of workpieces.

Due to P10 cemented carbide cutting tools mainly used for rough machining and semi-fine addition, it's a huge consumption. There is great economic value on extended P10 cemented carbide cutting life. 45 steel has the characteristic of low hardness and easy cutting. Therefore, the cutting of 45 steel with P10 carbide tool is a classic combination to study the cutting performance. The present work addresses the 
effect of EMCFP treatment on the surface roughness of workpieces by analyzing the effect of P10 cemented carbide cutting tools subjected to EMCFP treatment on the surface roughness of machined 45 steel workpieces. The effects of untreated and EMCFP-treated cutting tools on workpiece surface roughness, tool lifetime, friction coefficient, electron paramagnetic resonance (EPR) spectra, dislocation density, and residual stress are compared. This research provides scientific data and technical support for EMCFP technology with important scientific significance.

\section{Materials And Methods}

\subsection{Experiments}

The cutting experiments were conducted using a 31303C P10 cemented carbide cutting tool on a GCNC6135 lathe. The cylindrical workpieces were composed of 45 quenched and tempered steel with diameters of $90 \mathrm{~mm}$ and lengths of $300 \mathrm{~mm}$. 45 tempered steel is a kind of medium carbon steel. After heat treatment process, it is quenched first and then tempered at high temperature, which enhances its hardness and strength and maintains its good plasticity and toughness. 45 steel is widely processed into structural parts of various machines, and is the most commonly used type of steel in structured steel. Its chemical composition is shown in Table 1. In order to simulate the general rough machining and semi finish machining state, all experiments employed equivalent cutting parameters, which included a spindle speed of $560 \mathrm{r} / \mathrm{min}$, feed rate of $60 \mathrm{~mm} / \mathrm{min}$, and a cutting depth of $1 \mathrm{~mm}$. The wear state of the tools was evaluated after each interval of cutting an equivalent linear length of $95 \mathrm{~mm}$ until experiencing tool failure. As illustrated in Fig. 1, the wear on the flank face surfaces of the tools was inspected using a VMS 3020 imaging instrument (DongGuan ZhongLi Instrument Technology Co., Ltd., China). The surface roughness of the workpieces was measured using a Bruker ContourGT optical profiler. Then, the flank face wear $(\mathrm{VB})$ and average surface roughness $(\mathrm{Ra})$ values of the samples were input into a personal computer $(\mathrm{PC})$.

Table 1. Standard chemical composition of the 45 steel workpiece material (wt\%)

\begin{tabular}{|lllllllll|}
\hline Element & $\mathrm{Fe}$ & $\mathbf{C}$ & $\mathrm{Cr}$ & $\mathrm{Mn}$ & $\mathrm{Ni}$ & $\mathbf{P}$ & $\mathbf{S}$ & $\mathrm{Si}$ \\
Wt\% & $97.76-$ & $0.42 \rrbracket$ & $\leq 0.25$ & $0.50 \rrbracket$ & $\leq 0.25$ & $\leq 0.035$ & $\leq 0.035$ & $0.17 \rrbracket$ \\
& 99 & 0.50 & & 0.80 & & & & 0.37 \\
\hline
\end{tabular}

Friction tests were conducted using the ball-on-block reciprocating friction and wear tester presented in Fig. 2. The ball was composed of 45 steel and the block material was untreated and EMCFP-treated P10 cemented carbide. The load-carrying tests were performed with normal loads of $120 \mathrm{~N}$, and a reciprocation frequency of $3 \mathrm{~Hz}$ was applied with a test duration of 3000 cycles.

The dislocation densities of the P10 cemented carbide inserts were evaluated before and after EMCFP by analyzing four different XRD peak profiles obtained using diffractometer (Empyrean) based on the 
Williamson-Hall method, which separates the length and strain stress effects of the various diffraction peaks. First, we estimate the crystallite size $t$ of the P10 cemented carbide inserts as follows:

$$
B \operatorname{COS}(\theta)=\frac{K \lambda}{t}+4 \varepsilon \operatorname{Sin}(\theta)
$$

Where $B$ is the FWHM, $\theta$ is the diffraction angle, $K$ is a constant with a value of about $1, \lambda$ is the wavelength of the $X$-ray source, and $\varepsilon$ is the lattice microstrain which is a quarter fitting slope of line

$$
\begin{aligned}
& \left.\operatorname{Sin}(\theta), \frac{K \lambda}{t}\right) \text {. Then, the dislocation density is given as: } \\
& \text { graph }( \\
& \rho=\sqrt{\frac{3}{t^{2}} \times \frac{6 \pi \varepsilon^{2}}{b^{2}}}
\end{aligned}
$$

where $b$ is the Burger vector ( $b=2.61 \mathrm{~m}$ for $\mathrm{P} 10$ carbide).

The room-temperature ESR spectra of the P10 cemented carbide inserts were obtained before and after EMCFP using a JEOL JES-FA200 ESR spectrometer. The inserts were cut for testing by wire cutting to provide specimens with diameters $d=1 \mathrm{~mm}$ and lengths $L=5 \mathrm{~mm}$. The microwave power employed was $1 \mathrm{~mW}$, and the sweep width ranged from $0 \mathrm{mT}$ to $800 \mathrm{mT}$.

The residual stress of the tool flank faces was measured before and after EMCFP by X-ray diffraction (XRD) in the (2 12 2) diffraction plane using a Proto LXRD residual stress measurement system with an $\mathrm{Mn} \mathrm{Ka} \mathrm{X-ray} \mathrm{source.} \mathrm{Because} \mathrm{the} \mathrm{tool} \mathrm{flank} \mathrm{face} \mathrm{directly} \mathrm{contacts} \mathrm{with} \mathrm{the} \mathrm{workpiece,} \mathrm{the} \mathrm{surface} \mathrm{residual}$ stress was measured at three points on the tool flank face region illustrated in Fig. 3.

\subsection{Equipment and analysis of EMCFP}

The custom-designed equipment employed for applying EMCFP treatment to P10 cemented carbide cutting tools is illustrated in Fig. 4(a), and consisted mainly of a pulsed magnetic field generator, a pulsed electric field generator, and a water-cooled working chamber within which the carbide inserts are placed at atmospheric pressure for treatment. The pulsed magnetic field generator shown in Fig. 4(a) is composed of a capacitor discharge system and the magnetic induction coil shown in Fig. 4(b). The capacitor discharge system produces a square wave with a frequency of $1-10 \mathrm{~Hz}$ that passes through the magnetic induction coil to generate a magnetic field with an intensity ranging from $0-3.5 \mathrm{~T}$. The magnetic flux density of the generated magnetic field is measured by a gaussmeter placed at the center of the magnetic induction coil (Fig. 4(b)). The pulsed electric current generator shown in Fig. 4(a) is composed of a power supply system and a computer numerical controlled (CNC) pulse system. The power supply system converts a $380 \mathrm{~V}$ alternating current at $50 \mathrm{~Hz}$ to a square wave at a low voltage of 0-10.0 V with a maximum current value of $5000 \mathrm{~A}$. The standard EMCFP parameters employed in all experiments were a magnetic field intensity of $1.5 \mathrm{~T}$ and an electric signal amplitude of $1.2 \mathrm{~V}$ with a 
maximum current of $400 \mathrm{~A}$. The magnetic field pulses and electric current pulses are synchronized in all experiments, and the EMCFP treatment is conducted for $1 \mathrm{~min}$.

EMCFP treatment is a process in which electric and magnetic fields act on the tool simultaneously. In this process, electric and magnetic fields are coupled. The direction of the electric field is the same as that of the magnetic field.

\section{Results And Discussion}

\subsection{Influence of EMCFP on tool lifetime}

Figure 5 [17] presents images of P10 cemented carbide tool flank faces at the four standard stages of wear: initial worn, normal worn, acutely worn and tool failure. Because the flank face is predominantly subject to wear during the cutting process, the ISO 8688-1 standard defines tool wear states according to flank face wear (VB) values, and assigns VB values of $0.00-0.10 \mathrm{~mm}$ to the initial worn stage, VB values of $0.10-0.20 \mathrm{~mm}$ to the normal worn stage, VB values of $0.20-0.30 \mathrm{~mm}$ to the acutely worn stage, and VB values greater than $0.3 \mathrm{~mm}$ as the tool failure limit.

The VB values obtained for three untreated and three EMCFP-treated P10 cemented carbide tools are presented in Fig. 6. We note that all tool lifetime curves obtained conform to a standard tool wear mechanism, where the value of VB increased rapidly in the initial worn stage, increased at a lower rate in an approximately linear fashion during the normal worn stage, and finally increased rapidly again in the acutely worn stage as the tool approached failure. The results indicate that EMCFP treatment increased the average tool lifetime significantly by a factor of 1.92 .

\subsection{Influence of EMCFP on workpiece surface roughness}

The workpiece topographies obtained at cutting lengths of $900 \mathrm{~mm}$ and $1800 \mathrm{~mm}$ when machining with untreated and EMCFP-treated P10 cemented carbide tools are presented in Figs. 7(a) and (b), respectively. The results indicate that the surface roughness of the workpieces was significantly reduced when machined by the EMCFP-treated cutting tool owing to the enhanced surface smoothness of the tool.

The workpiece topographies obtained at cutting lengths of $2700 \mathrm{~mm}$ and $3600 \mathrm{~mm}$ when machining with untreated and EMCFP-treated P10 cemented carbide tools are presented in Figs. 8(a) and (b), respectively. These results obtained at greater cutting lengths very clearly demonstrate the benefits of employing the proposed EMCFP treatment, where the cutting furrows of the workpiece surface machined by the untreated tool are particularly deep and jagged because the VB value of the tool is greater than $0.2 \mathrm{~mm}$, which is indicative of an acutely worn tool with a very rough surface.

Sections of the actual machined workpiece surfaces subjected to cutting lengths of $3600 \mathrm{~mm}$ were removed for three-dimensional (3D) imaging using a VHX-2000 optical microscope (Kenyence Corp. of America). The 3D images and corresponding topologies obtained are presented in Figs. 9(a) and (b), respectively. The results clearly reveal that the surface roughness of the machined workpiece was greatly 
reduced after subjecting the cutting tool to EMCFP treatment, and the profile height decreased by $22.81 \%$ to $22 \mu \mathrm{m}$ relative to the conditions obtained with the untreated tool.

The Ra values $(\mu \mathrm{m})$ of the machined workpieces and the corresponding VB values $(\mathrm{mm})$ of the untreated and EMCFP-treated tools are listed in Table 2 for different cutting lengths. The results indicate that the Ra values of the workpiece machined by the EMCFP-treated tool decreased significantly, particularly at cutting lengths of $1800 \mathrm{~mm}$ and $2700 \mathrm{~mm}$. In addition, while the changes in the corresponding VB values of the tools are much less than those of the Ra values of the workpiece at cutting lengths of $1800 \mathrm{~mm}$ and $2700 \mathrm{~mm}$, these changes are much greater than those of the Ra values at cutting lengths of $900 \mathrm{~mm}$ and $3600 \mathrm{~mm}$. Accordingly, we can conclude that the decreased tool wear leading to an enhanced tool lifetime contributes strongly to the reduced surface roughness of the machined workpieces.

Table 2. Comparison of the average surface roughness $(\mathrm{Ra})$ values $(\mathrm{nm})$ of the machined workpieces and the corresponding flank face wear (VB) values (mm) of the untreated and EMCFP-treated tools.

\begin{tabular}{|lllllll|}
\hline $\begin{array}{l}\text { Cutting length } \\
(\mathbf{m m})\end{array}$ & $\begin{array}{l}\text { Ra- } \\
\text { Untreated }\end{array}$ & Ra-EMCFP & Difference & $\begin{array}{l}\text { VB- } \\
\text { Untreated }\end{array}$ & $\begin{array}{l}\text { VB- } \\
\text { EMCFP }\end{array}$ & Difference \\
\hline $900 \mathrm{~mm}$ & $\begin{array}{l}1051.999 \\
\mathrm{~nm}\end{array}$ & $\begin{array}{l}887.989 \\
\mathrm{~nm}\end{array}$ & $15.590 \% \downarrow$ & $0.100 \mathrm{~mm}$ & $0.06 \mathrm{~mm}$ & $40 \% \downarrow$ \\
\hline $1800 \mathrm{~mm}$ & $\begin{array}{l}1408.746 \\
\mathrm{~nm}\end{array}$ & $\begin{array}{l}913.863 \\
\mathrm{~nm}\end{array}$ & $35.139 \% \downarrow$ & $0.201 \mathrm{~mm}$ & $0.16 \mathrm{~mm}$ & $20.40 \% \downarrow$ \\
\hline $2700 \mathrm{~mm}$ & $\begin{array}{l}1853.088 \\
\mathrm{~nm}\end{array}$ & $\begin{array}{l}1125.766 \\
\mathrm{~nm}\end{array}$ & $39.249 \% \downarrow$ & $0.203 \mathrm{~mm}$ & $0.18 \mathrm{~mm}$ & $11.33 \% \downarrow$ \\
\hline $3600 \mathrm{~mm}$ & $\begin{array}{l}1076.265 \\
\mathrm{~nm}\end{array}$ & $\begin{array}{l}1538.121 \\
\mathrm{~nm}\end{array}$ & $25.919 \% \downarrow$ & $0.290 \mathrm{~mm}$ & $0.20 \mathrm{~mm}$ & $31.03 \% \downarrow$ \\
\hline
\end{tabular}

The surface waviness observed over a lateral distance perpendicular to the cutting direction is another important index reflecting the surface roughness of a machined surface. This condition is illustrated schematically in Fig. 10. The waveform in Fig. 10 (b) was obtained from Fig. 10 (a). The extracted wave profiles indicative of wave width $W$ and wave height $R$ for workpieces subjected to machined by untreated and EMCFP-treated P10 cemented carbide tools are presented in Fig. 11. Comparing the wave width $W$ and wave height $R$ in Fig. 11, the wave width $W$ obtained with the untreated tool and the treated tool were the same. However, wave height $R$ is different, especially in Fig. 11 (b) and Fig. 11 (c).

Additional surface waviness features, including the root mean square deviation (Rq), maximum profile peak height (Rp), and the maximum profile valley depth (Rv) along the lateral $x$ direction are illustrated in Fig. 12, and their corresponding calculation formulas based on the average position of the surface $Z(x)$ over the lateral space considered are presented as well. The calculated values of Rq, Rp, and Rv obtained for workpieces machined by untreated and EMCFP-treated tools are listed in Table 3 . The results indicate that the values of all features decreased after subjecting the cutting tool to EMCFP treatment, particularly 
Rv. Accordingly, we can conclude that the waviness of the microstructure of the machined surface was decreased to a large extent after EMCFP, and the cutting process became more stable.

Table 3. Comparison of root mean square deviation (Rq; $\mathrm{nm}$ ), maximum profile peak height (Rp; $\mathrm{nm}$ ), and the maximum profile valley depth $(\mathrm{Rv} ; \mathrm{nm})$ values obtained for workpieces machined by untreated and EMCFP-treated tools.

\begin{tabular}{|lllllll|}
\hline $\begin{array}{l}\text { Cutting length } \\
(\mathrm{mm})\end{array}$ & $\begin{array}{l}\text { Rq- } \\
\text { Untreated }\end{array}$ & $\begin{array}{l}\text { Rq- } \\
\text { EMCFP }\end{array}$ & $\begin{array}{l}\text { Rp- } \\
\text { Untreated }\end{array}$ & $\begin{array}{l}\text { Rp- } \\
\text { EMCFP }\end{array}$ & $\begin{array}{l}\text { Rv- } \\
\text { Untreated }\end{array}$ & $\begin{array}{l}\text { Rv- } \\
\text { EMCFP }\end{array}$ \\
\hline 900 & 1339.071 & 1126.44 & 4467.328 & 3207.091 & 3018.959 & 2356.863 \\
\hline 1800 & 1953.701 & 1178.258 & 5628.238 & 3078.597 & 3519.171 & 2374.656 \\
\hline 2700 & 2275.394 & 1384.879 & 6295.996 & 3997.206 & 4408.783 & 2586.526 \\
\hline 3600 & 2495.876 & 2092.815 & 6596.894 & 6645.089 & 4901.345 & 2942.691 \\
\hline
\end{tabular}

\subsection{Influence of EMCFP on the friction coefficient}

The results of ball-on-block reciprocating friction testing obtained for untreated and EMCFP-treated P10 cemented carbide materials are presented in Fig. 13 according to the mean friction coefficient calculated at each reciprocating cycle of testing. The average friction coefficient obtained over the full 1800 cycles for the untreated sample was 0.583 , while this value decreased by $11.4 \%$ to 0.516 after EMCFP treatment. Moreover, we note from the results that the mean friction coefficient values obtained at each testing cycle for the treated sample were more uniform over the full number of cycles compared with those of the untreated sample.

\subsection{Influence of EMCFP on the ERP spectra of cutting tools}

The effect of EMCFP treatment on the ERP spectra of P10 cemented carbide samples is shown in Fig. 15. Here, an increased EPR signal intensity represents a larger number of unpaired electrons in the sample. We note that the peak values of the EPR spectra increased by $7.28 \%$ at the signal crest and $29 \%$ at the signal trough after EMCFP treatment. Magnetic field can increase the number of unpaired electrons which can change the state of free radical form (Singlet) $S$ to (Triplet) $T[7,19]$. The combine energy of electron pair is strong in S state, but weak in T state. In T state, the force of dislocation and pinning centers is weak, even depinning and move. The dislocation multiply lead the plasticity improvement

\subsection{Influence of EMCFP on the dislocation density of cutting tools}

The full XRD patterns and the four individual diffraction peaks (WC (001), TiC (100), TiC (200), and WC (101)) of untreated and EMCFP-treated P10 cemented carbide samples are presented in Figs. 14(a) and (b), respectively. The four individual XRD peaks are observed to have shifted toward lower diffraction angles after EMCFP treatment, which is indicative of reduced residual stress [20]. The dislocation densities were calculated using Eqs. (1) and (2), and the results are listed in Table 4. We note that the dislocation density increased by $38 \%$ after EMCFP treatment. Under the combined impacts of the electro- 
plastic effect [21,22] and the magnetostriction effect [23], the EMCFP treatment increased dislocation mobility by decreasing the activation energy of dislocation movement, which promoted internal stress release. In addition, the EMCFP process provides the necessary energy for dislocation motions to occur, resulting in the homogenization of the dislocation distribution in the material [7]. Simultaneously, applied electric fields reduce entanglement between dislocations, which removes obstacles toward dislocation slippage, so that the material exhibits higher plasticity [24].

Table 4. Comparison of dislocation density values obtained for untreated and EMCFP-treated P10 cemented carbide tools

\begin{tabular}{|lll|}
\hline & Untreated & Treated \\
\hline Dislocation density $\left(\times 10^{15}\right)$ & 1.4527 & 2.0101 \\
\hline
\end{tabular}

\subsection{Influence of EMCFP on the surface residual stress of cutting tools}

The residual stress values obtained at the same three points on the flank face surfaces of P10 cemented carbide tools before and after EMCFP treatment are listed in Table 5. The results indicate that residual stress values at all three points of the flank face surfaces decreased significantly after EMCFP treatment, and the average residual stress value of the three points was reduced by $51.4 \%$ compared with that of the untreated tool. The decreased residual stress can improve the mechanical properties of tool [25] and improve the tool wear resistance, thus decrease the workpiece surface roughness. Accordingly, we can conclude that EMCFP treatment can reduce the workpiece surface roughness significantly due to reduced residual stress of the flank face surface.

Table 5. Residual stress values of three points on the flank face regions illustrated in Fig. 13 of P10 cemented carbide tools before and after EMCFP treatment.

\begin{tabular}{|llll|}
\hline Measurement point & Untreated (MPa) & Treated (MPa) & Difference \\
\hline 1 & -129 & -74 & $43 \% \downarrow$ \\
\hline 3 & -146 & -70 & $52 \% \downarrow$ \\
\hline Average value & -150 & -64 & $57 \% \downarrow$ \\
\hline
\end{tabular}

\subsection{The relationship of tool lifetime, workpiece surface roughness, the friction coefficient, the dislocation density, and residual stress}

Dislocation, as a crystal defect, produces a special stress field. EMCFP can effectively increase the dislocation density and make the dislocation more uniform. Dislocation homogenization can affect the tool friction coefficient and residual stress. Dislocation homogenization can reduce the lattice distortion and thus reduce the tool friction coefficient. The friction coefficient of tools directly affects the workpiece 
surface roughness. When the friction coefficient of the tool is reduced, the flank face wear can be directly reduced, thus improving the life of the tool. Dislocation homogenization can also reduce tool residual stress and improve tool life[26]. Fig. 16 showed the relationship between tool lifetime, workpiece surface roughness, the friction coefficient, the dislocation density, and residual stress.

\section{Conclusions}

This work investigated the effect of pulsed EMCFP treatment applied to P10 cemented carbide tools on the surface roughness of machined workpieces for the first time. The effects of untreated and EMCFPtreated cutting tools on the surface roughness of 45 steel workpieces, tool lifetime, friction coefficient, EPR spectra, dislocation density, and residual stress were compared. The extensive experimental results support the following conclusions.

i. The average surface roughness of workpieces machined using the EMCFP-treated cutting tool decreased by $39.2 \%$, and the values of four surface waviness indexes were significantly decreased as well.

ii. The EMCFP treatment increased tool lifetime by a factor of 1.92. Accordingly, EMCFP increased the wear resistance of the tools and reduced surface irregularities on the tool cutting surface.

iii. The average friction coefficient at the cutting tool/workpiece interface decreased by $11.4 \%$ after applying EMCFP treatment. Accordingly, the tribological properties of P10 cemented carbide were improved.

iv. The intensity of EPR signal peaks was enhanced due to the increased dislocation density obtained after the EMCFP treatment.

v. The dislocation density of the tool material increased by $38 \%$ after EMCFP treatment. Accordingly, EMCFP can increase dislocation mobility by decreasing the activation energy, while providing the necessary energy for dislocation motions to occur, resulting in the homogenization of the dislocation distribution in the material.

vi. The residual stress on the flank face surfaces of cutting tools deceased by $51.4 \%$ after EMCFP treatment. Accordingly, EMCFP is a potential method for enhancing the mechanical properties of metals.

These results collectively demonstrate that the proposed EMCFP treatment is a fast, economical, environmentally friendly, and effective metal-enhancement technology that can reduce the surface roughness of workpiece materials significantly, reduce the residual stress of cutting tools, and extend cutting tool lifetimes. Accordingly, EMCFP represents a highly beneficial means of supporting the sustainable manufacturing of machined parts.

The paper has not been published previously, that it is not under consideration for publication elsewhere, and that if accepted it will not be published elsewhere in the same form, in English or in any other language, without the written consent of the publisher. 


\section{Declarations}

\section{The statement of authors' contributions:}

Fu Zhong: Formal analysis, Investigation, Resources, Data Curation, Writing - Review \& Editing. Min Yuan: Conceptualization, Writing - Original Draft. Dehao Meng: Resources, Data Curation. Li Wang: Conceptualization. Jie Wang: Project administration. Jian Liu: Methodology. Kunlan Huang: Funding acquisition. Yankang Tian: Supervision.

Funding information The authors wish to acknowledge the financial support by the National Nature Science Foundation of China (no.51705348), Sichuan science and technology program (no.2019YFG0361) and the Research Funds for the Central University (no.2019SCUH0013).

\section{Declaration of interest statement}

The author(s) declared no potential conflicts of interest with respect to the research, authorship, and/or publication of this article.

The paper does not contain material which has been published previously, by the current authors or by others, of which the source is not explicitly cited in the paper.

Upon acceptance of an article by the journal, the author(s) will be asked to transfer the copyright of the article to the publisher. This transfer will ensure the widest possible dissemination of information.

\section{References}

1. Liu G, Huang C, Zhu H, Liu Z, Liu Y, Li C (2017) The modified surface properties and fatigue life of Incoloy A286 face-milled at different cutting parameters. Materials Science and Engineering: A 704:19. doi:https://doi.org/10.1016/j.msea.2017.07.072

2. Alam Z, Jha S (2017) Reprint of "Modeling of surface roughness in ball end magnetorheological finishing (BEMRF) process". Wear 376-377:194-202. doi:https://doi.org/10.1016/j.wear.2017.04.007

3. Wang M, Wang J (2012) CHMM for tool condition monitoring and remaining useful life prediction. doi:10.1007/s00170-011-3536-7

4. Vasumathy D, Meena A (2017) Influence of micro scale textured tools on tribological properties at tool-chip interface in turning AISI 316 austenitic stainless steel. Wear 376-377:1747-1758. doi:https://doi.org/10.1016/j.wear.2017.01.024

5. Dehghani A, Amnieh SK, Tehrani AF, Mohammadi A (2017) Effects of magnetic assistance on improving tool wear resistance and cutting mechanisms during steel turning. Wear 384-385:1-7. doi:https://doi.org/10.1016/j.wear.2017.04.023

6. Tharajak J, Palathai T, Sombatsompop N (2017) The effects of magnetic field-enhanced thermal spraying on the friction and wear characteristics of poly(ether-ether-ketone) coatings. Wear 372373:68-75. doi:https://doi.org/10.1016/j.wear.2016.11.021 
7. Zhang X, Zhao Q, Cai Z, Pan J (2020) Effects of Magnetic Field on the Residual Stress and Structural Defects of Ti-6Al-4V. Metals 10 (1). doi:10.3390/met10010141

8. Xu Q, Li K, Cai Z, Wu Y (2019) Effect of Pulsed Magnetic Field on the Microstructure of TC4 Titanium Alloy and Its Mechanism. doi:10.11900/0412.1961.2018.00257

9. Ma L, Wang X, Liang Z, Liu Y, Zhang D (2019) Machining mechanism in pulsed magnetic treatment for micro-tools. The International Journal of Advanced Manufacturing Technology 101 (9):23912406. doi:10.1007/s00170-018-3105-4

10. Song Y-L, Yu C, Miao X, Han X-H, Qian D-S, Chen X (2017) Tribological Performance Improvement of Bearing Steel GCr15 by an Alternating Magnetic Treatment. Acta Metallurgica Sinica (English Letters) 30 (10):957-964. doi:10.1007/s40195-017-0587-2

11. Xi X, Xia Y, Hu Y (2018) The Effects of Magnetic Treatment on the Tribological Behavior of AISI 1045 Steel under Lubricated Conditions. Tribology Transactions 61 (4):671-682. doi:10.1080/10402004.2017.1390180

12. Xiang S, Zhang X (2020) Residual Stress Removal Under Pulsed Electric Current. Acta Metallurgica Sinica (English Letters) 33 (2):281-289. doi:10.1007/s40195-019-00941-z

13. Jung J, Ju Y, Morita Y, Toku Y (2017) Enhancement of fatigue life of aluminum alloy affected by the density of pulsed electric current. International Journal of Fatigue 103:419-425. doi:https://doi.org/10.1016/j.ijfatigue.2017.06.021

14. Xiang S, Zhang X (2019) Dislocation structure evolution under electroplastic effect. Materials Science and Engineering: A 761:138026. doi:https://doi.org/10.1016/j.msea.2019.138026

15. Liu J, Wei C, Yang G, Wang L, Wang L, Wu X, Jiang K, Yang Y (2018) A Novel Combined Electromagnetic Treatment on Cemented Carbides for Improved Milling and Mechanical Performances. Metallurgical and Materials Transactions A 49 (10):4798-4808. doi:10.1007/s11661018-4740-y

16. Yuan M, Wang J, Wang L, Zhong F, Huang K, Tian Y (2021) Electromagnetic coupling field strengthening of WC-TiC-Co cermet tools. Ceramics International 47 (3):3747-3759. doi:https://doi.org/10.1016/j.ceramint.2020.09.232

17. Yuan M, Wang J, Wang M, Huang K, Wang L, Tian Y (2020) Enhanced carbide tool life by the electromagnetic coupling field for sustainable manufacturing. The International Journal of Advanced Manufacturing Technology 108 (11):3905-3914. doi:10.1007/s00170-020-05612-3

18. Guo YB, Li W, Jawahir IS (2009) Surface Integrity Characterization and Prediction in Machining of Hardened and Difficult-to-Machine Alloys: A State-of-Art Research Review and Analysis. Machining Science and Technology 13 (4):437-470. doi:10.1080/10910340903454922

19. Golovin YI (2004) Magnetoplastic Effects in Solids. doi:10.1134/1.1744954

20. Wang Z, Wang Y (2011) Existence of quasiperiodic solutions and Littlewood's boundedness problem of super-linear impact oscillators. Applied Mathematics and Computation 217 (13):6417-6425. doi:https://doi.org/10.1016/j.amc.2011.01.037 
21. Song H, Wang Z-j (2012) Improvement of mechanical properties of cold-rolled commercially pure $\mathrm{Ti}$ sheet by high density electropulsing. Transactions of Nonferrous Metals Society of China 22 (6):1350-1355. doi:https://doi.org/10.1016/S1003-6326(11)61325-3

22. He W, Wang L, Zhuang G (2019) Intrinsic current driven by electromagnetic electron drift wave turbulence in the tokamak pedestal region. Plasma Physics and Controlled Fusion 61 (11):115016. doi:10.1088/1361-6587/ab4682

23. Li G, Cheng J, Wang H, Li C (2019) Influence of Static Magnetic Field on Microstructure and Properties of 7055 Aluminum Alloy. Xiyou Jinshu Cailiao Yu Gongcheng/Rare Metal Materials and Engineering 48 (4):1036-1045

24. Xu X-L, Zheng G-G, Wang H-D, Wang T (2017) Research progress on the application of electro-plastic effect in materials processing. doi:10.3969/j.issn.1007-2012.2017.06.001

25. Abdoos M, Bose B, Rawal S, Arif AFM, Veldhuis SC (2020) The influence of residual stress on the properties and performance of thick TiAIN multilayer coating during dry turning of compacted graphite iron. Wear 454-455:203342. doi:https://doi.org/10.1016/j.wear.2020.203342

26. Shao Q, Wang G, Wang H, Xing Z, Fang C, Cao Q (2021) Improvement in uniformity of alloy steel by pulsed magnetic field treatment. Materials Science and Engineering: A 799:140143.

doi:https://doi.org/10.1016/j.msea.2020.140143

\section{Figures}

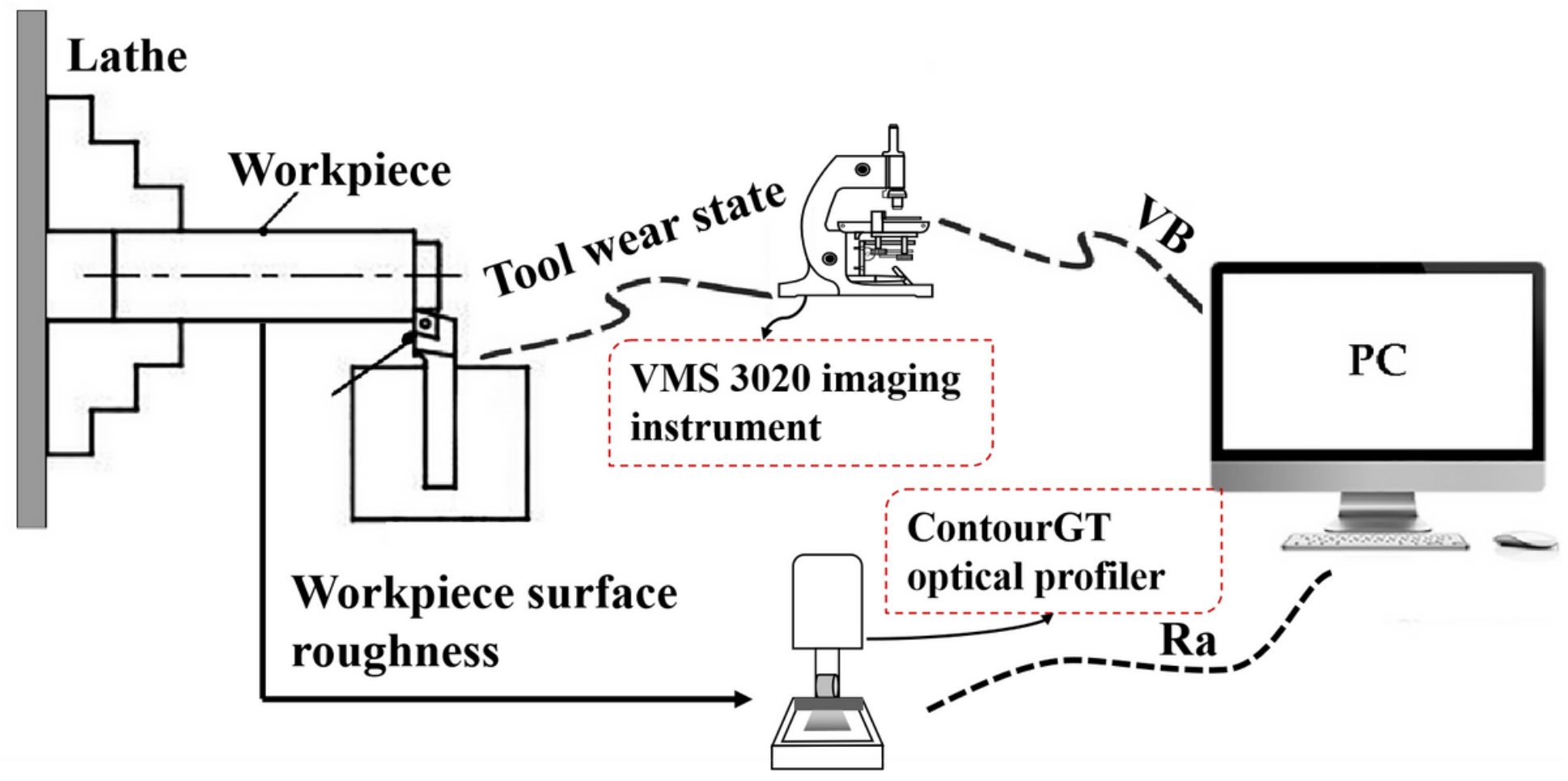

Figure 1 


\section{Loading}
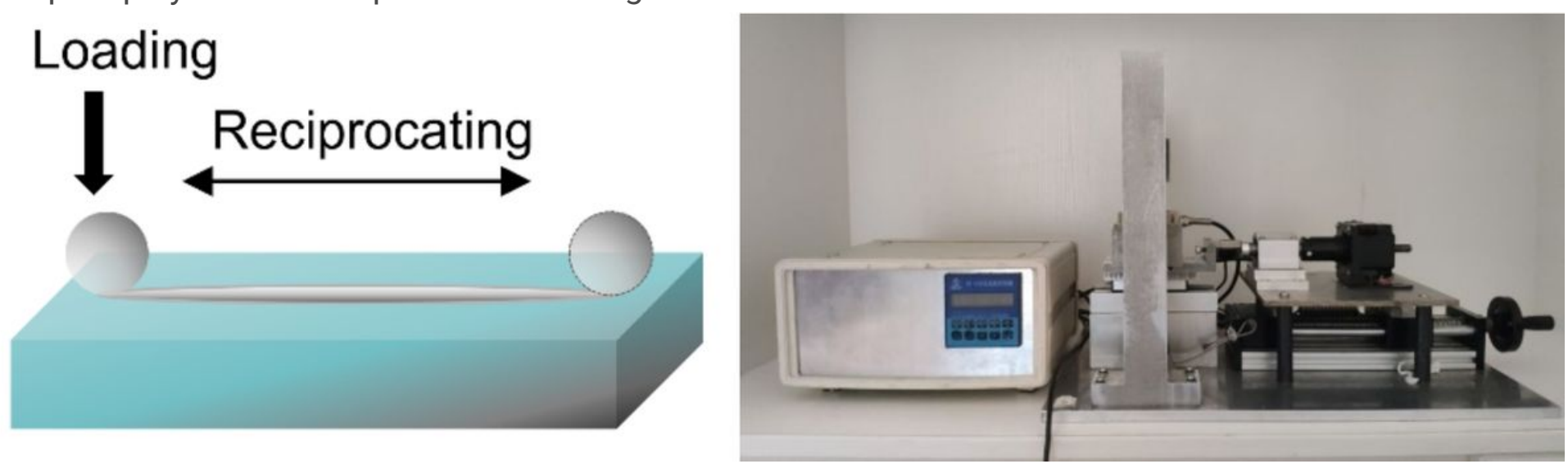

\section{Figure 2}

Schematic (left) illustrating the processing of the ball-on-block reciprocating friction and wear tester unit (right) employed for evaluating the friction coefficients of untreated and EMCFP-treated P10 cemented carbide tools.

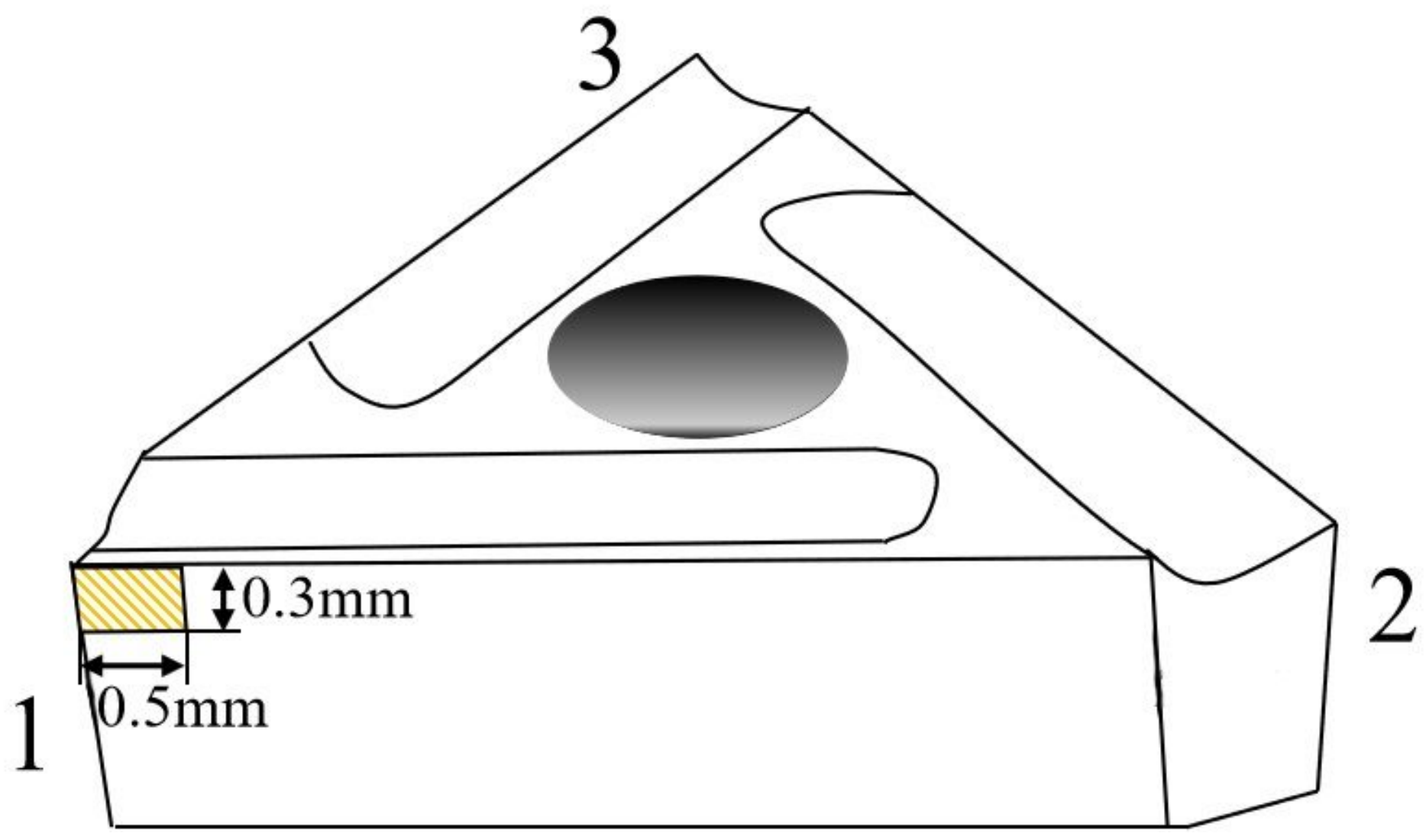

Figure 3

Schematic illustrating the flank face region of P10 cemented carbide tools employed for residual stress testing 
(a) Magnetic field generator

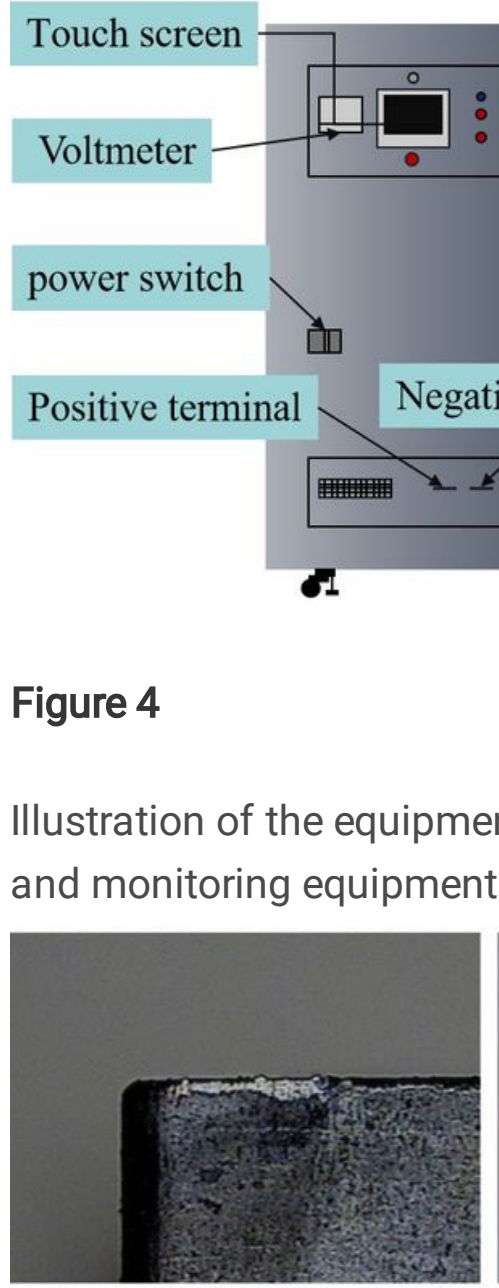

Initial worn

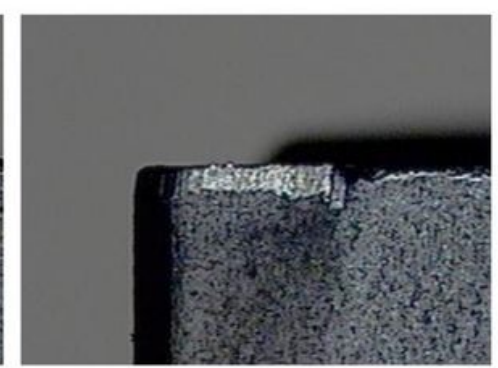

Normal worn
Electric field generator

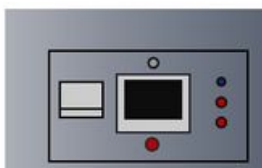

Carbide insert

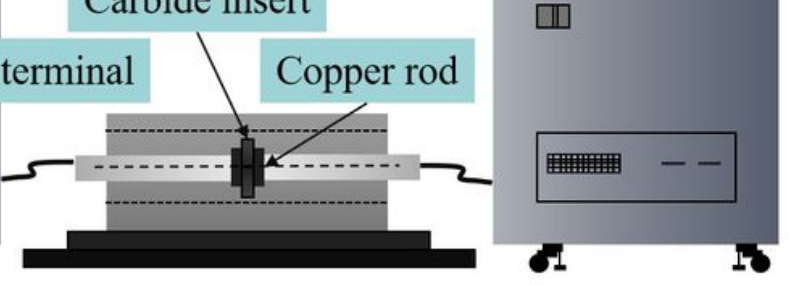

(b)

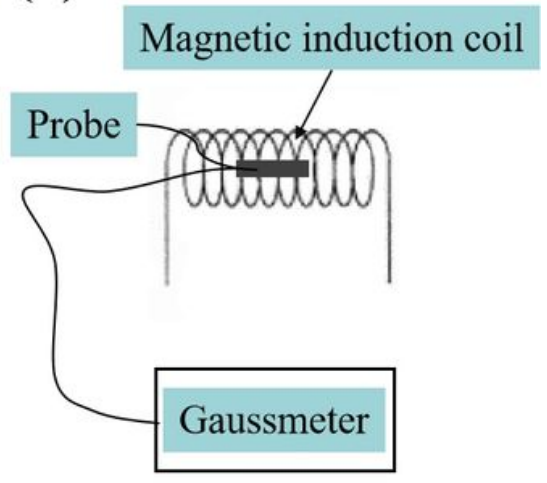

\section{Figure 5}

Images of P10 cemented carbide tools at the four standard states of progressive tool wear 


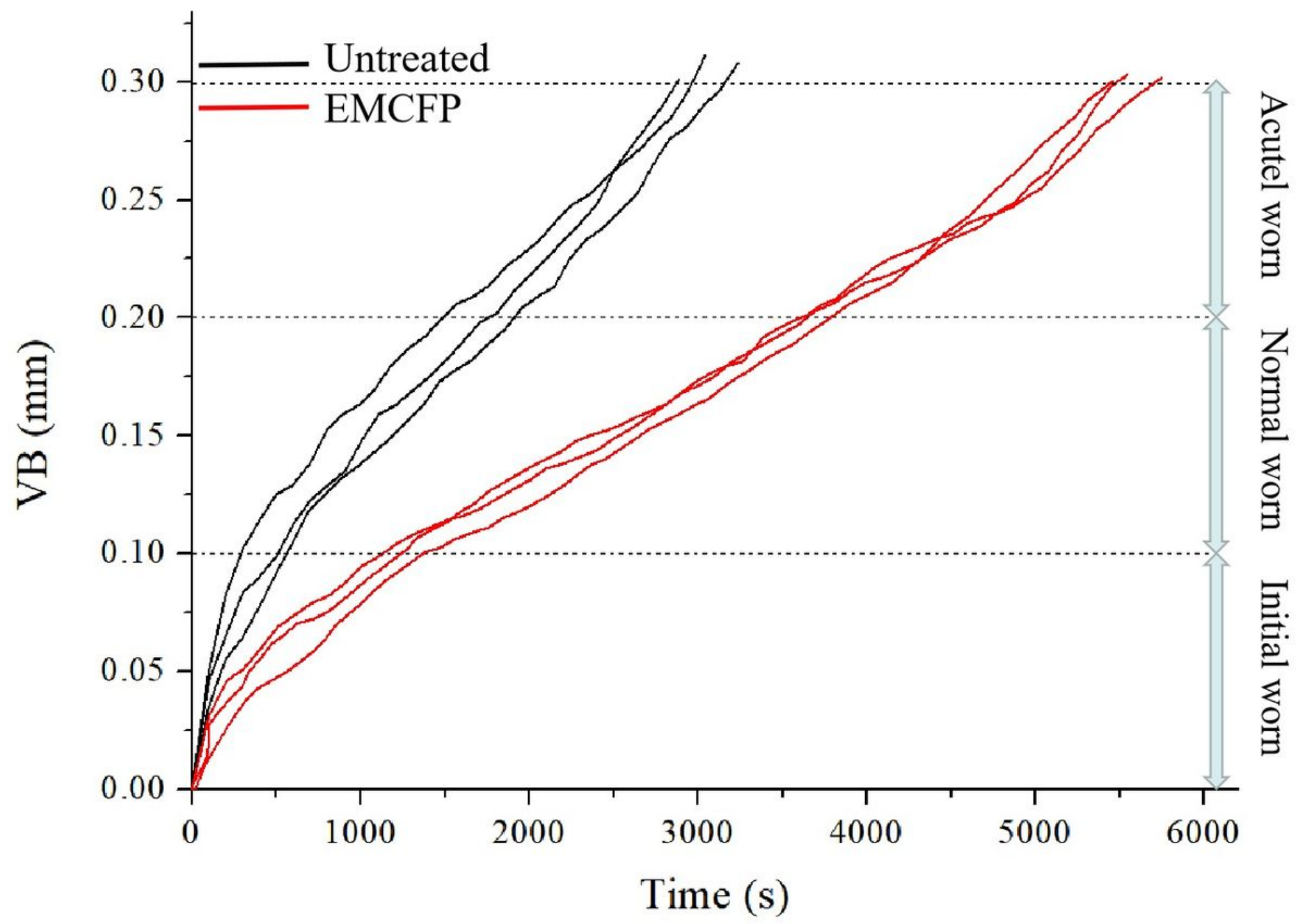

Figure 6

Experimental flank wear (VB) values indicative of the tool wear process obtained with respect to cutting time for three untreated and three EMCFP-treated P10 cemented carbide tools.

\section{Untreated}
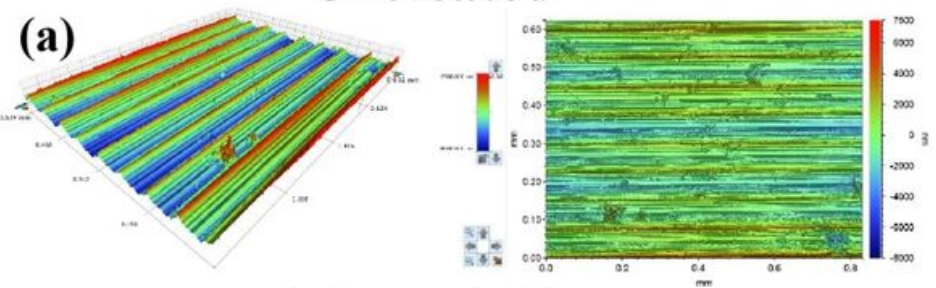

Cutting length $=900 \mathrm{~mm}$
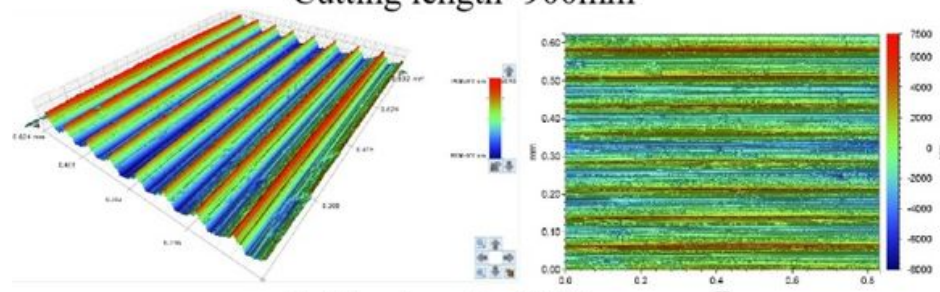

Cutting length $=1800 \mathrm{~mm}$

EMCFP

(b)

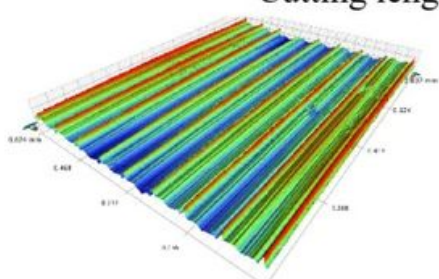

Cutting length $=1800 \mathrm{~mm}$
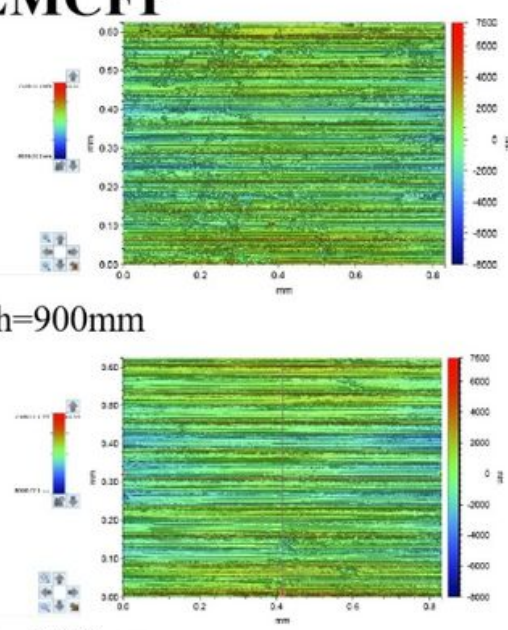

Figure 7 
Workpiece topologies obtained at cutting lengths of $900 \mathrm{~mm}$ and $1800 \mathrm{~mm}$ when machining with untreated (a) and EMCFP-treated (b) P10 cemented carbide tools.

\section{Untreated}

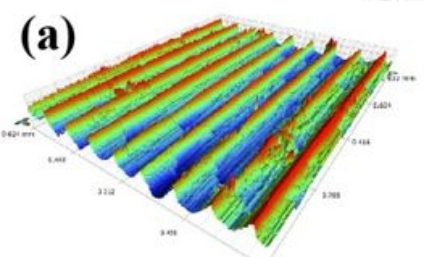

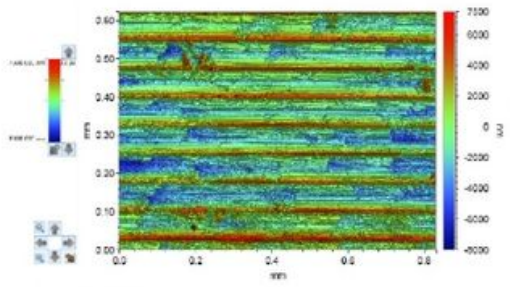

Cutting length $=2700 \mathrm{~mm}$
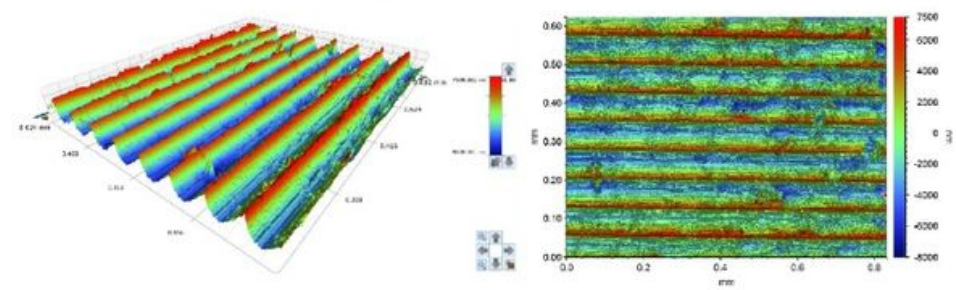

Cutting length $=3600 \mathrm{~mm}$
EMCFP
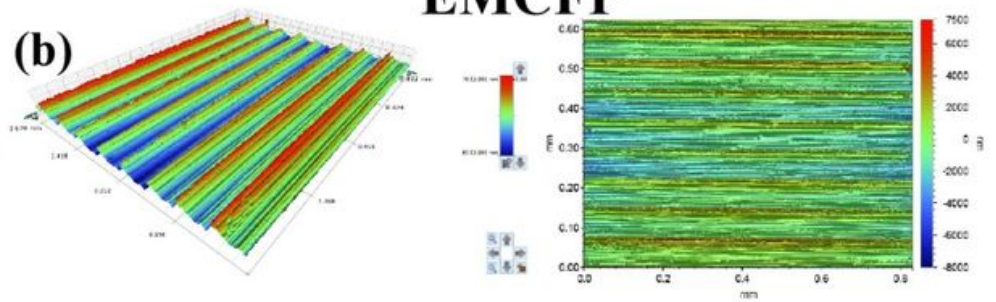

Cutting length $=2700 \mathrm{~mm}$
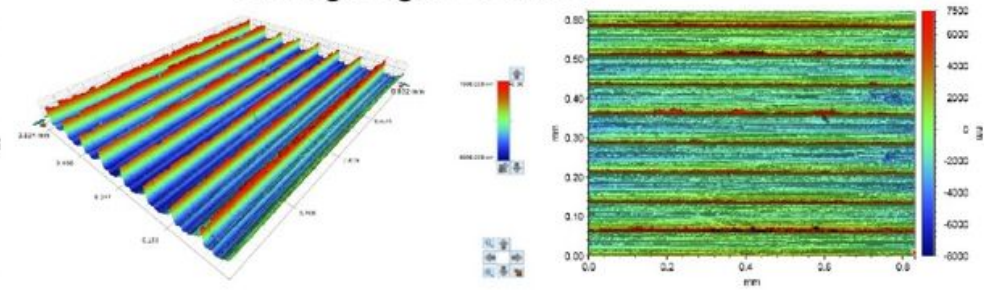

Cutting length $=3600 \mathrm{~mm}$

\section{Figure 8}

Workpiece topologies obtained at cutting lengths of $2700 \mathrm{~mm}$ and $3600 \mathrm{~mm}$ when machining with untreated (a) and EMCFP-treated (b) P10 cemented carbide tools.

\section{Untreated}

(a)
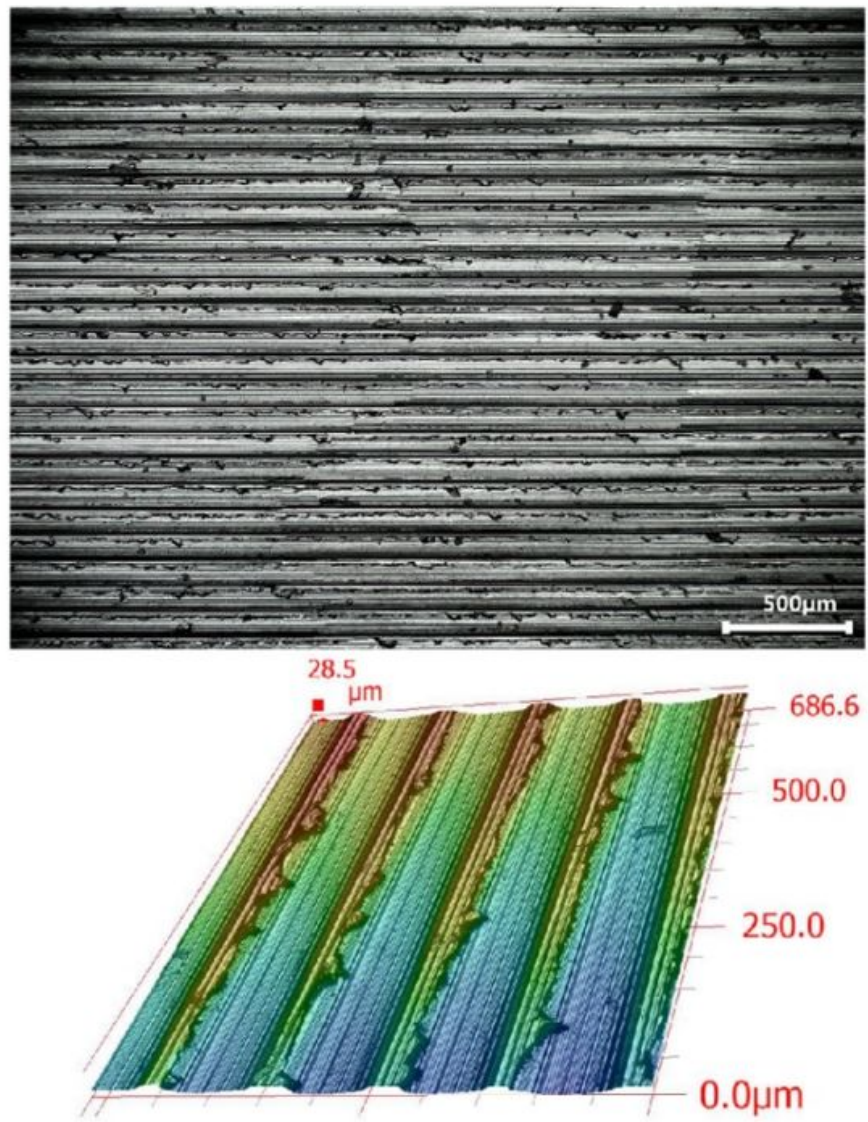

500.0

250.0

$0.0 \mu \mathrm{m}$
EMCFP
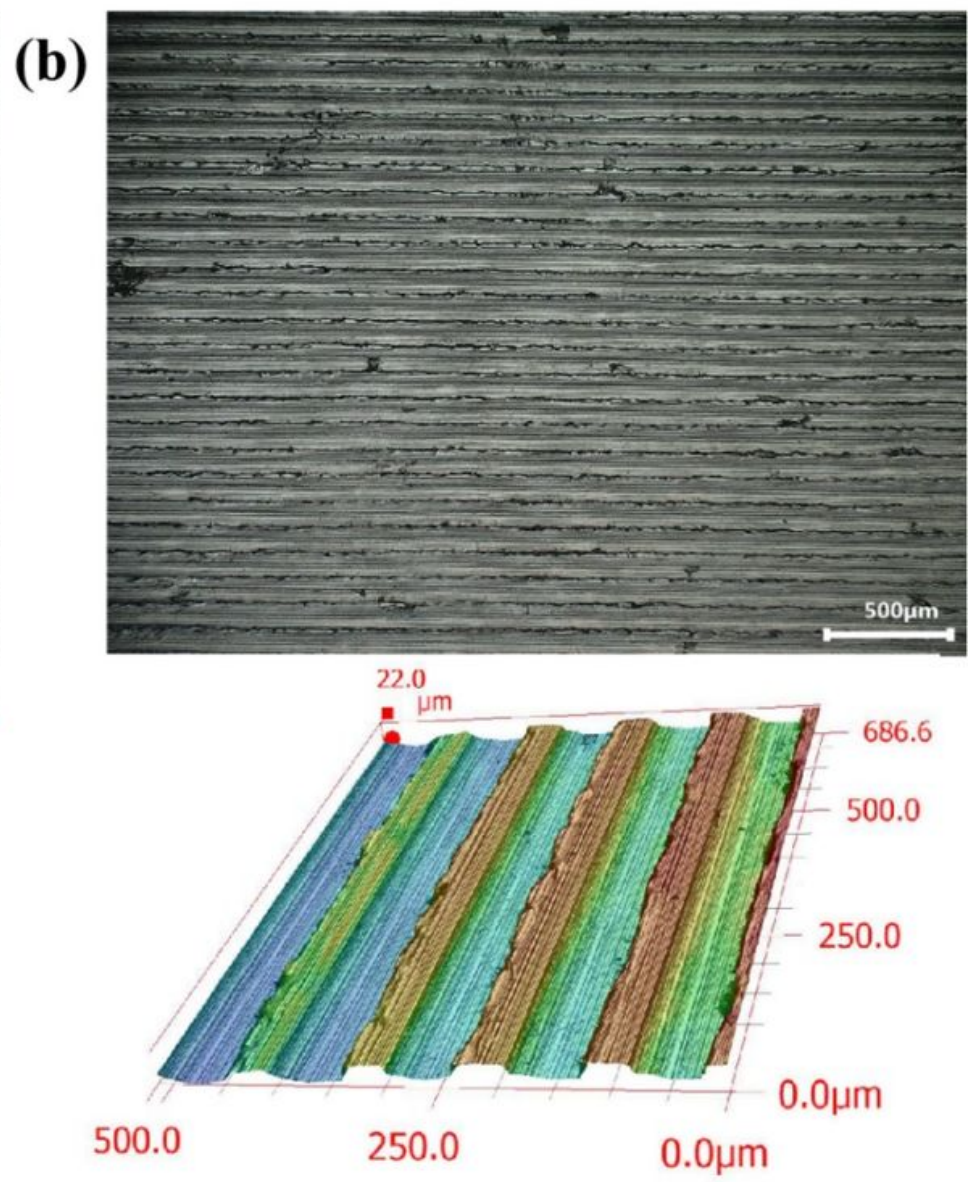


\section{Figure 9}

Three-dimensional (3D) optical imaging results of workpiece surfaces subjected to cutting lengths of $3600 \mathrm{~mm}$ by untreated (a) and EMCFP-treated (b) P10 cemented carbide tools.

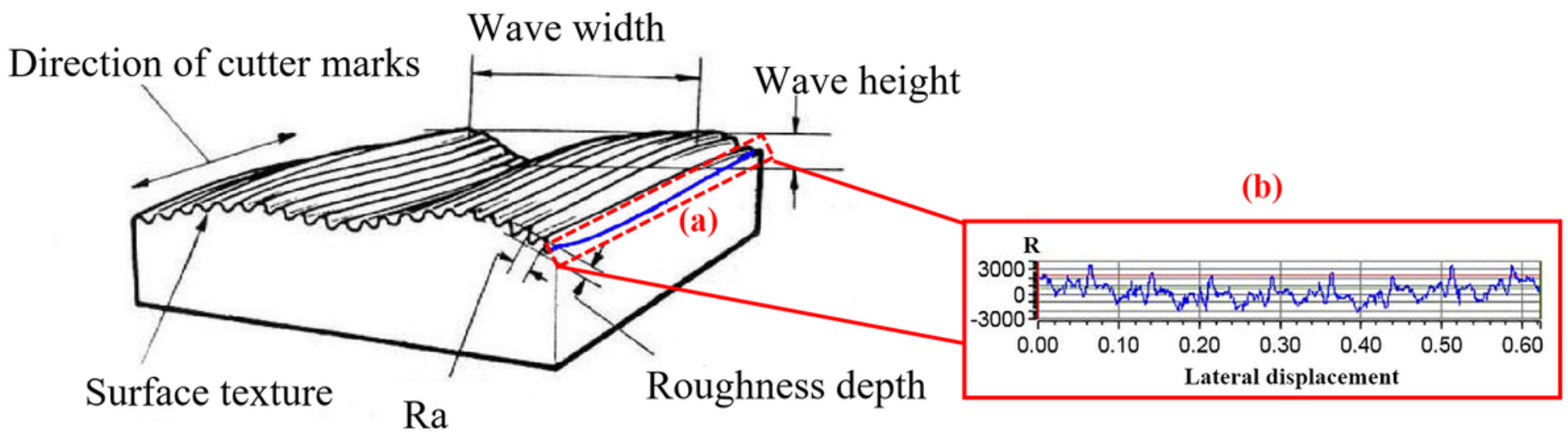

\section{Figure 10}

Schematic illustrating the lateral waviness perpendicular to the cutting direction on the surfaces of machined workpieces. 

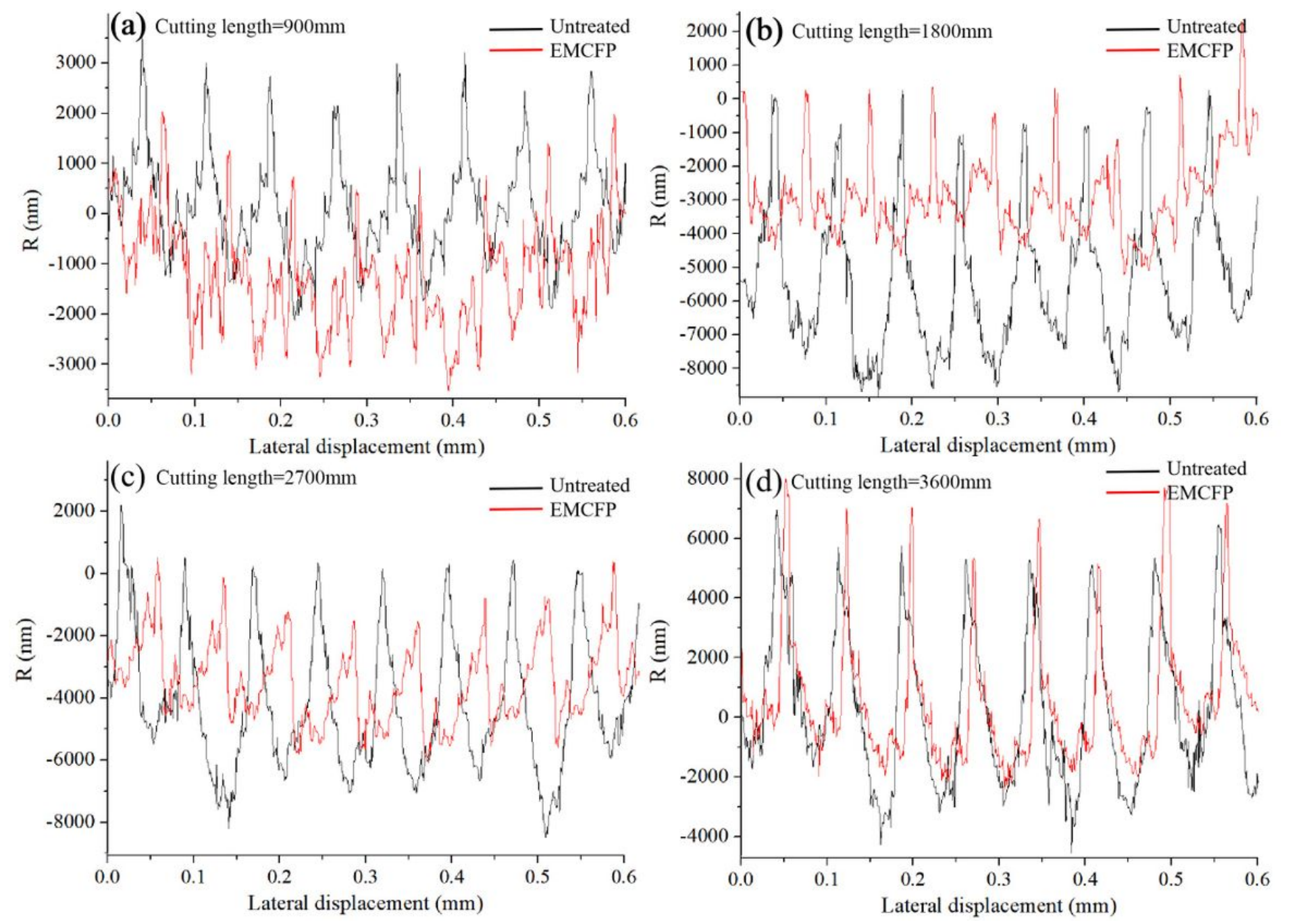

Figure 11

Wave heights $\mathrm{R}$ with respect to lateral displacement along the workpiece surfaces machined by untreated and EMCFP-treated P10 cemented carbide tools.

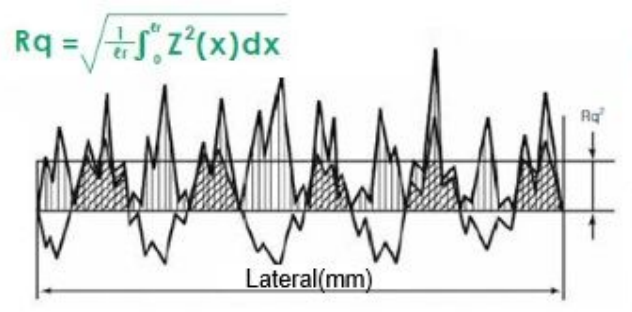

$R p=\max (Z(x))$

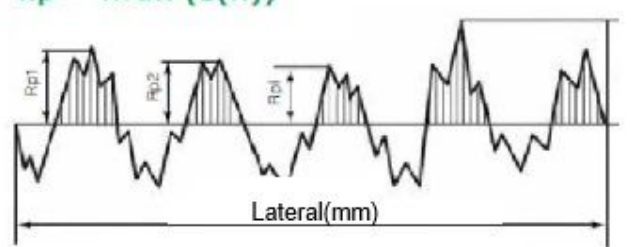

$R v=|\min (Z(x))|$

\section{Figure 12}

Schematic illustrating surface waviness features along the lateral $x$ direction and their corresponding calculation formulas based on the average position of the surface $Z(x)$ over the lateral space considered. 


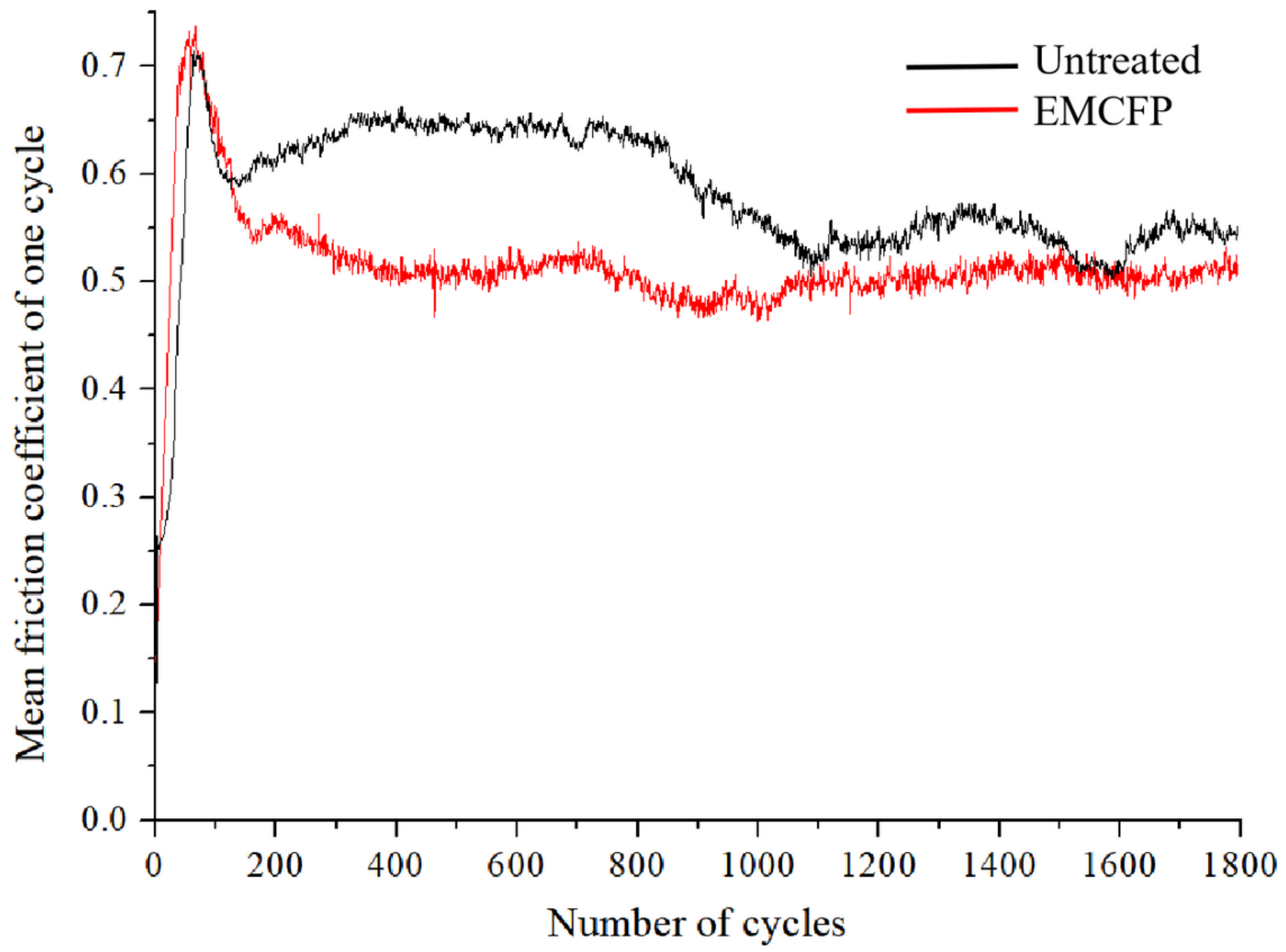

Figure 13

Results of ball-on-block reciprocating friction testing obtained for untreated and EMCFP-treated P10 cemented carbide materials in terms of the mean friction coefficient calculated at each reciprocating cycle of testing. 


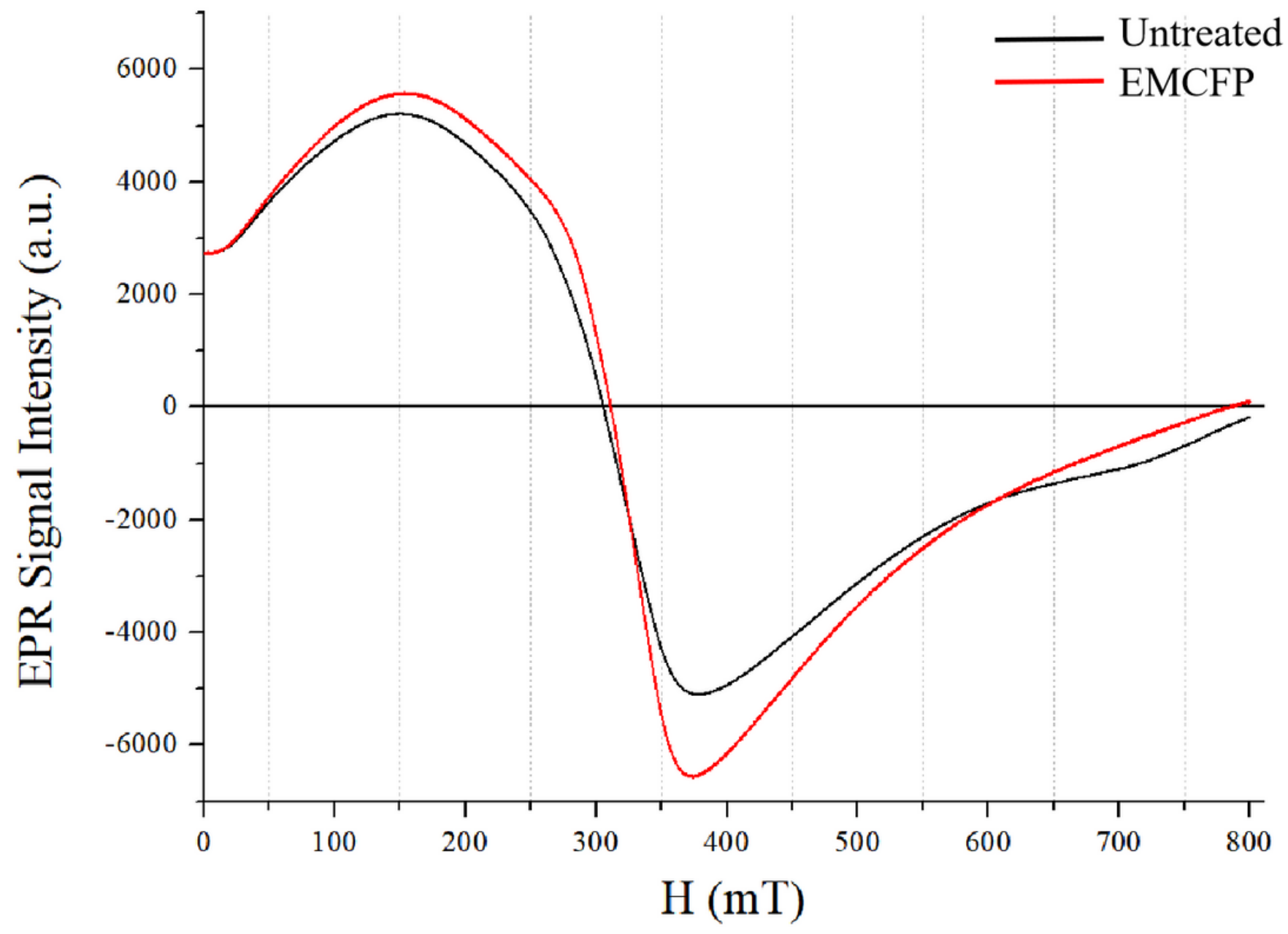

Figure 14

Effect of EMCFP treatment on the ERP spectra of P10 cemented carbide samples 

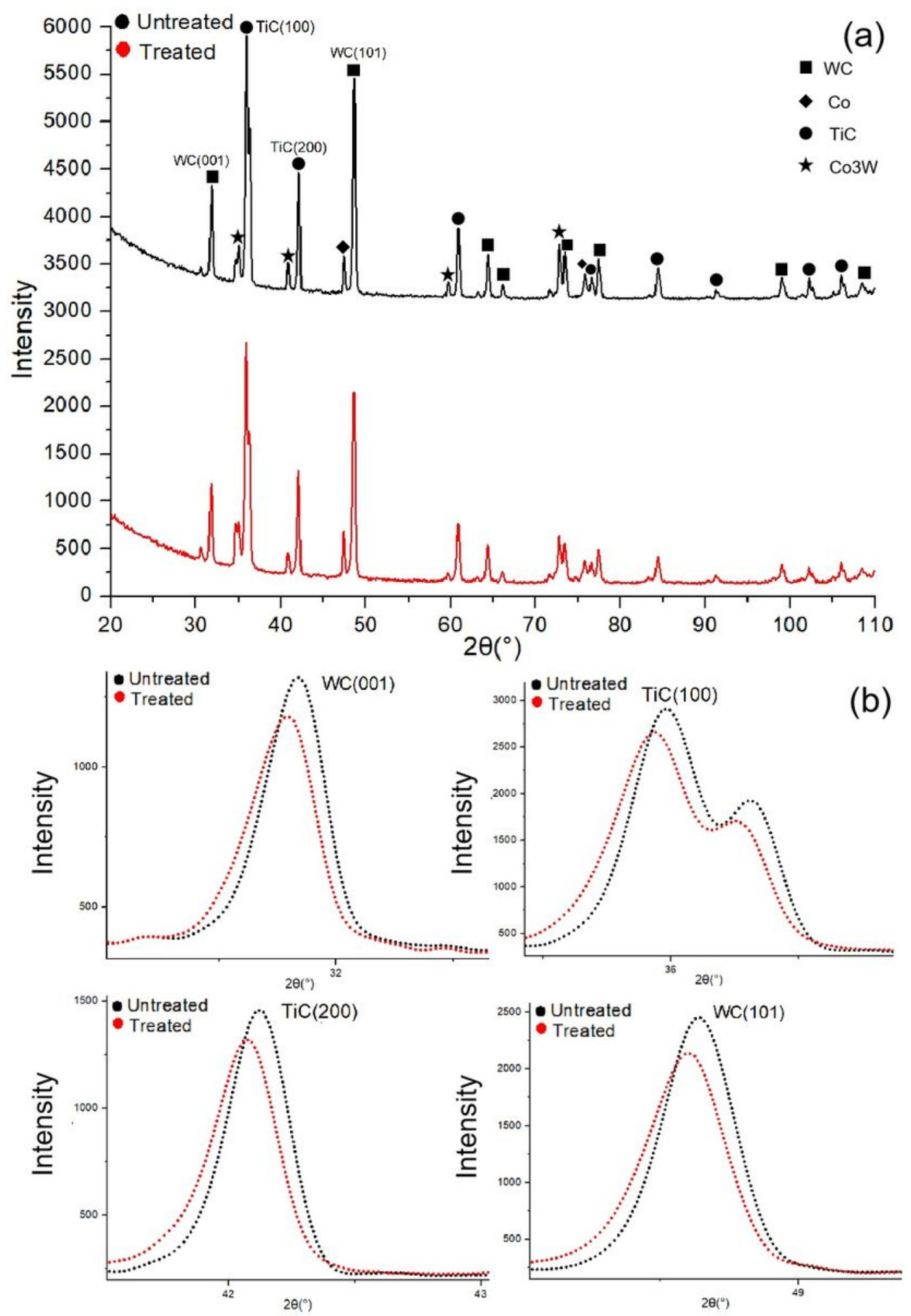

Figure 15

XRD patterns obtained for P10 cemented carbide samples before and after EMCFP treatment: (a) full diffraction patterns; (b) four individual diffraction peaks. 


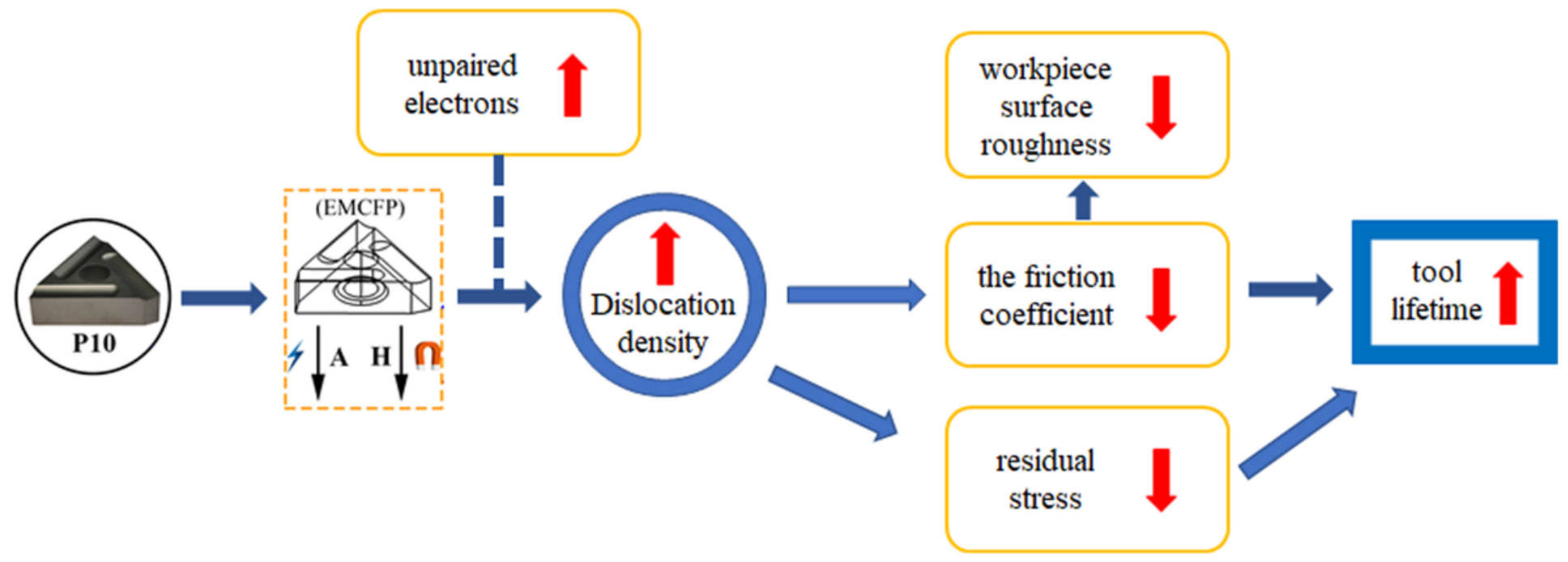

Figure 16

The relationship between tool lifetime, workpiece surface roughness, the friction coefficient, the dislocation density, and residual stress. 